\title{
Screening of Cognitive Impairment in the Dialysis Population: A Scoping Review
}

\author{
Aye San $^{a} \quad$ Balaji Hiremagalur ${ }^{a} \quad$ Wendy Muircroft $^{b} \quad$ Laurie Grealish $^{a}{ }^{c}$ \\ ${ }^{a}$ Gold Coast Health, Southport, QLD, b Southern Adelaide Palliative Service, Adelaide, SA, \\ and 'Menzies Health Institute Queensland and School of Nursing and Midwifery, Griffith \\ University, Southport, QLD, Australia
}

\section{Keywords}

Dialysis · Cognitive impairment $\cdot$ Cognitive screening $\cdot$ Scoping review

\begin{abstract}
Background: Cognitive impairment in end-stage kidney disease patients on dialysis is increasingly common. This study aimed to review the practice of screening and to evaluate the evidence on cognitive impairment prevalence in this population. Methods: This scoping review of studies summarises the evidence on cognitive impairment in dialysis populations. The search included the Medline, CINAHL, Embase, PsycINFO, PubMed, and Cochrane Library databases for English-language articles published between 2000 and 2015. A total of 46 articles were reviewed. Results: The studies were of prospective observational design, with the majority conducted in the haemodialysis population. The reported prevalence of cognitive impairment ranged from 6.6 to $51 \%$. Three screening tools were consistently used. Conclusion: While cognitive impairment is recognised in the dialysis population, there is paucity of screening data. The design of prospective comparisons ideally includes established screening instruments, particularly the Montreal Cognitive Assessment, to determine the optimal results for this population. Translation of established screening tools to increase the inclusion of people from other cultural and language groups is required. Regular screening can enhance the timing to introduce home-based care support and advance care planning discussions.
\end{abstract}


San et al.: Screening of Cognitive Impairment in the Dialysis Population: A Scoping Review

\section{Introduction}

Globally, developments in medicine and greater understanding of human behaviour have led to significant progress in reducing mortality and increasing the average life expectancy in developed countries. Despite improvements in healthcare and longevity, there is very little reduction in the overall effect of non-fatal diseases on population health [1]. This trend has resulted in end-stage kidney disease (ESKD) being increasingly a disease of the elderly. According to the Australia and New Zealand Dialysis and Transplant Registry (ANZDATA), in 2015 , approximately two-thirds of prevalent dialysis patients were $\geq 65$ years old, and onethird were $\geq 75$ years old [2].

Based on published international studies, internationally the prevalence of dementia is between 5 and $9 \%$ of the population [3]. The prevalence of dementia in patients with ESKD, who are on dialysis is largely unknown as studies of cognition in this population have excluded patients with dementia. The reported prevalence of cognitive impairment among patients with ESKD, as assessed using neuropsychological tests, varies from 16 to 38\% [4]. In a recent systematic review, people treated with haemodialysis were found to have more cognitive impairment than the general population in most cognitive domains [5].

There is international agreement that population-based screening of people aged $\geq 65$ years for mild cognitive impairment should not be undertaken, primarily on the grounds that progress from mild cognitive impairment to dementia is uncertain [6-8]. Routine screening, however, may have value in ESKD populations, with reported rates of cognitive impairment approximately three-fold higher than in the general population. Cognitive impairment in this population may interfere with capacity for self-care and informed decision-making, which puts individuals at risk for poor outcomes. If cognitive impairment is recognised early, potentially reversible causes such as delirium and depression can be identified and treated. Early recognition may provide an opportunity for care planning before the dementia becomes advanced [4].

A scoping review was conducted to provide insight into the practice of screening for cognitive impairment in people with ESKD on dialysis. The review focused on optimal timing and valid instruments for screening for cognitive impairment in patients on dialysis. The prevalence of cognitive impairment using a screening tool in the studies was also determined. The purpose of the review was to identify the gaps in what is known to guide future research.

\section{Materials and Methods}

The methodology framework for scoping reviews as described by Arksey and O'Malley [9] was used. A scoping review was selected to rapidly review the literature on screening for cognitive impairment in dialysis patients to identify gaps in the evidence base, and to identify whether a full systematic review is feasible or relevant.

Identification of Research Questions

Through an initial review of the literature on cognitive impairment in dialysis patients, the following research questions were identified: (1) What are the validated tools for screening for cognitive impairment in dialysis patients? (2) What is the prevalence of cognitive impairment in the dialysis population when a screening tool is administered? (3) What are the optimal conditions and timings in relation to haemodialysis sessions to screen for cognitive impairment?

Identification of Relevant Studies

The Medline, CINAHL, Embase, PsycINFO, PubMed, and Cochrane Library databases were searched for English-language articles published between 2000 and 2015. All peer-reviewed prospective observational trials that used a screening tool for cognitive impairment in haemodialysis and peritoneal dialysis populations were included. The search strategy is reported in Table 1. Studies on patients with non-dialysis chronic 
Dementia

and Geriatric

Cognitive Disorders

\begin{tabular}{l|l}
\hline \multicolumn{2}{l}{ Dement Geriatr Cogn Disord 2017;44:182-195 } \\
\hline DOI: 10.1159/000479679 & $\begin{array}{l}\text { c 2017 S. Karger AG, Basel } \\
\text { www.karger.com/dem }\end{array}$ \\
\hline
\end{tabular}

San et al.: Screening of Cognitive Impairment in the Dialysis Population: A Scoping Review

Table 1. Search concepts and keywords

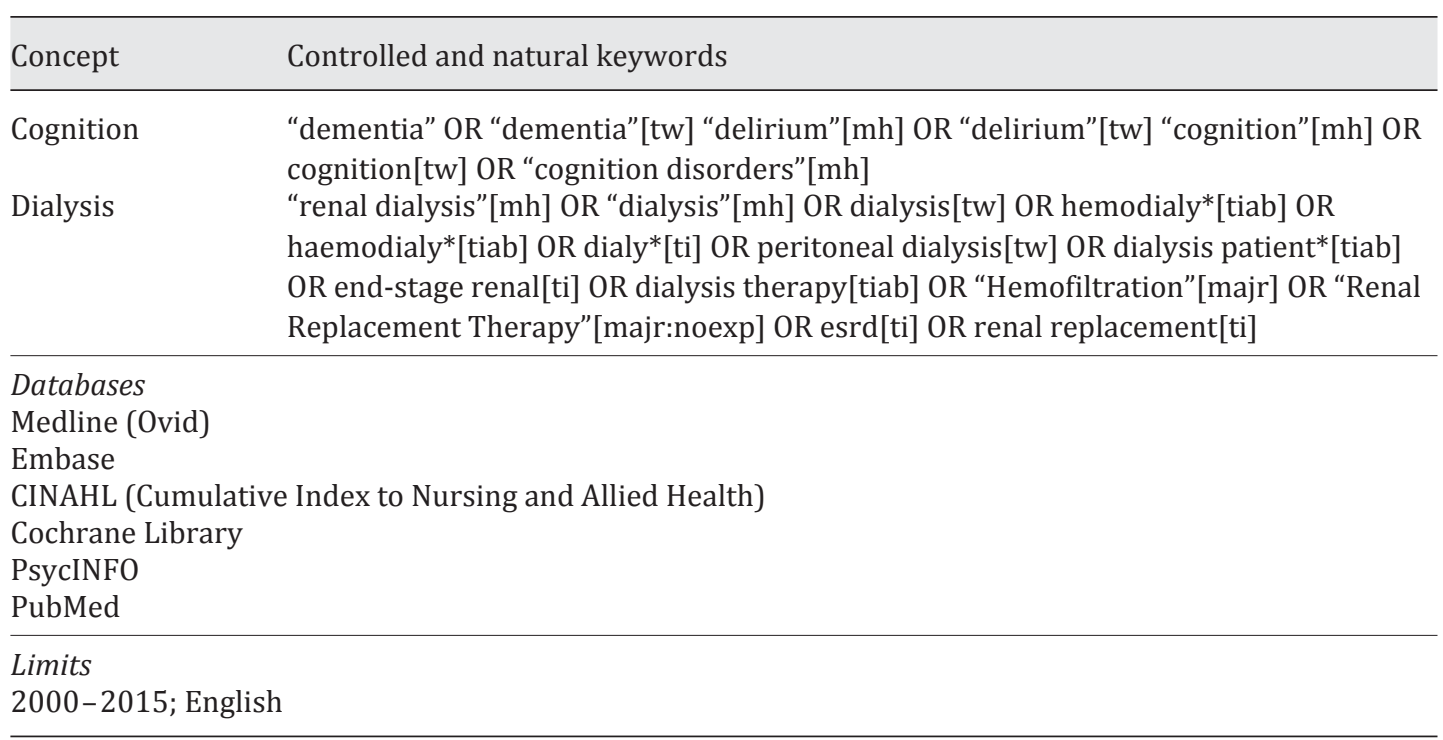

kidney disease, paediatrics studies, animal studies, case reports, and review articles were excluded. Other exclusion criteria included dialysis dementia or aluminium toxicity, uremic encephalopathy, dialysis disequilibrium, acute kidney injury, intensive care unit dialysis, and other secondary causes for cognitive impairment such as subdural haematoma.

\section{Study Selection}

Studies were selected for review in a two-step process. The study authors worked in pairs to review the titles and abstracts in step 1 and then the articles in step 2. When a review pair disagreed about inclusion or exclusion, the team met to discuss and agree. The process of selection through stepwise exclusion is shown in Figure 1.

\section{Charting of Data}

Initially, data were catalogued and sorted using Endnote XV and Microsoft Excel. Two investigators reviewed each article, with rotation of each pair of reviewers to enhance reliability. Data were summarised and entered into the Excel spreadsheet and organised by author, year of publication, study location, intervention type and comparator (if any), duration of the intervention, study populations, aims of the study, methodology, outcome measures, and important results.

\section{Summarising and Reporting of Results}

In contrast to a systematic review, the scoping study identifies a broad range of studies irrespective of study design and quality to present an overview of all the material selected for review [9]. Description of the geographic source of studies, purpose and types of cognitive assessment tools, and prevalence of cognitive impairment in the renal dialysis population was undertaken. In reporting the prevalence of cognitive impairment, the cut-off used by the study authors was noted. The type of research methods adopted was also described.

\section{Results}

A total of 334 articles were found through the database searches. There were 46 studies meeting the inclusion criteria for final analysis [10-55]. An overview of the reviewed articles is presented in Table 2. 
San et al.: Screening of Cognitive Impairment in the Dialysis Population: A Scoping Review

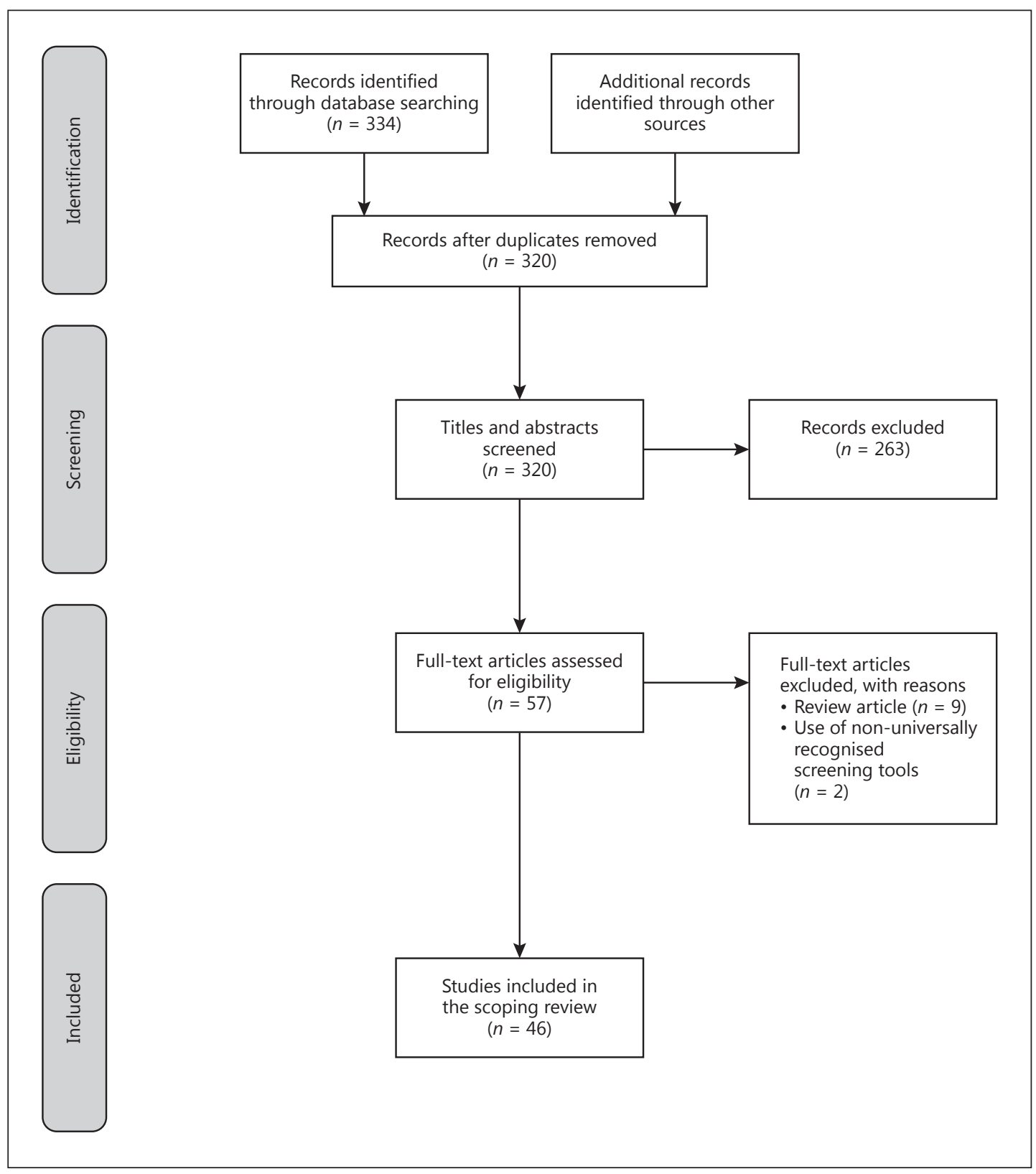

Fig. 1. PRISMA flow diagram showing the studies included and excluded.

The included studies were conducted across 17 countries, and 13 out of the 46 studies were conducted in the USA. Of note, none of the included studies were from the United Kingdom, Canada, or Australia.

All of the studies were prospective observational studies, with 21 studies including a control group for comparison. The focus for the majority of the studies was to assess the prevalence of risk factors for, and correlates of, cognitive impairment in the dialysis population. Thirty-five out of the 46 studies were conducted in the haemodialysis population, 9 studies in both the peritoneal dialysis and haemodialysis population, and 1 in the peritoneal dialysis population. Most studies included patients aged $\geq 65$ years, and only 2 studies were conducted focusing on a younger population, with a mean age of $<40$ years $[35,55]$. 
Dementia

and Geriatric

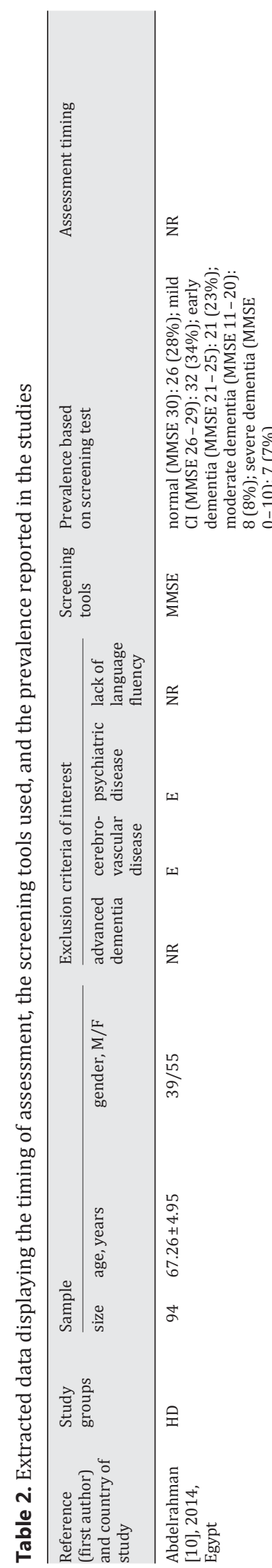

Dement Geriatr Cogn Disord 2017;44:182-195

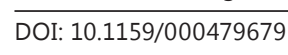

C) 2017 S. Karger AG, Basel
www.karger.com/dem

San et al.: Screening of Cognitive Impairment in the Dialysis Population: A Scoping Review
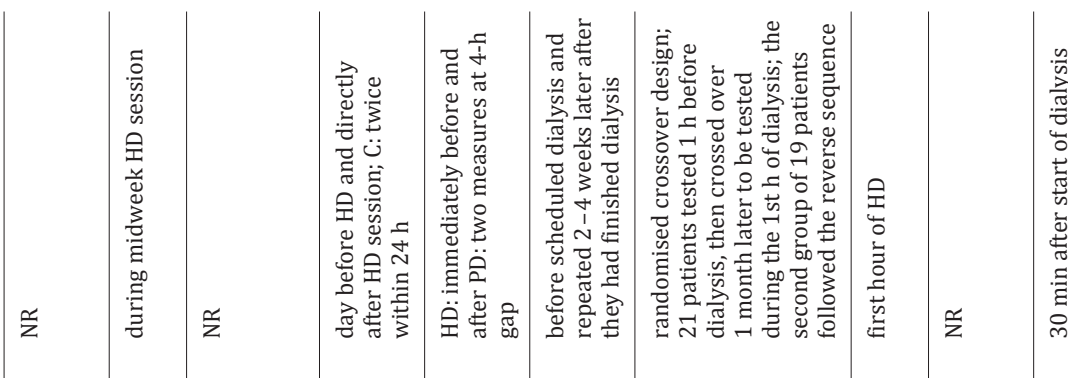

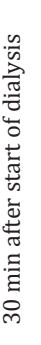
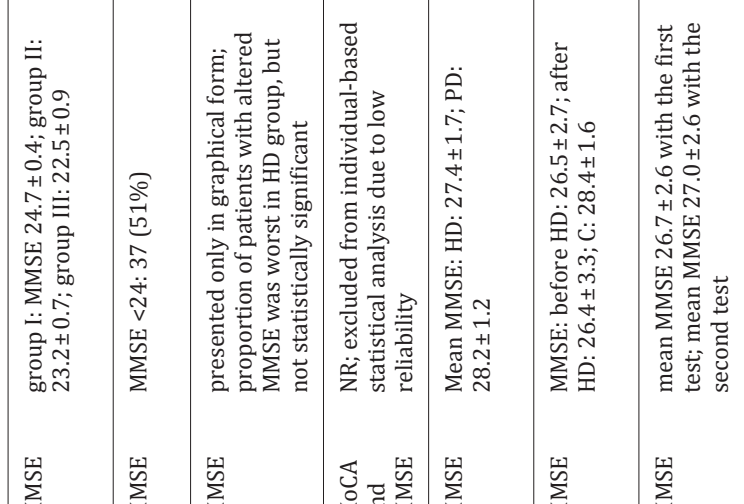

$\sum_{i}^{5}$

$\sum_{\Sigma}^{\infty}$

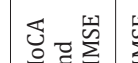

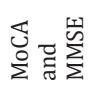

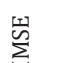

(2)
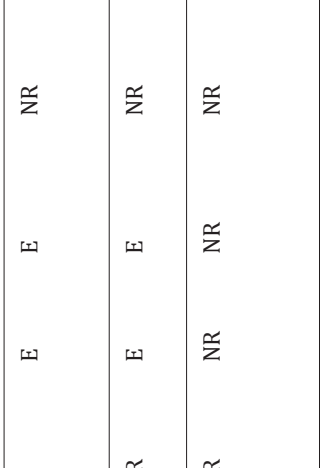

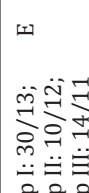

言言言

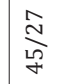

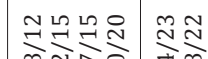

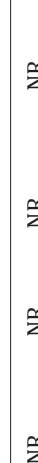

ํํำ

네

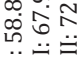

言言言 章

$\therefore$

걱ㄷㅇ 엉

대ㅇㅛㅡㄱ

$\sum_{0}^{\infty} \sum_{\infty}^{\infty}$

낵음
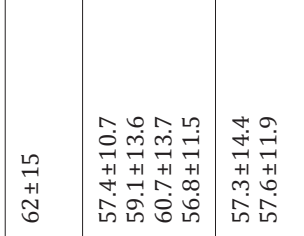

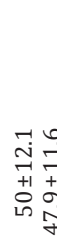

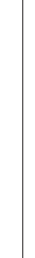

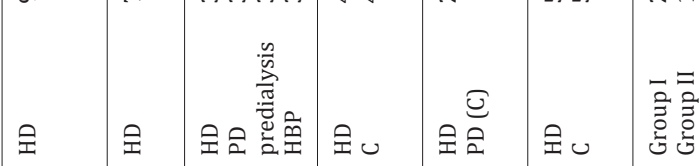

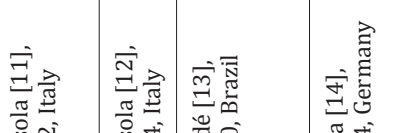

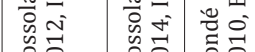

to 
Dementia

and Geriatric
Cognitive Disorders

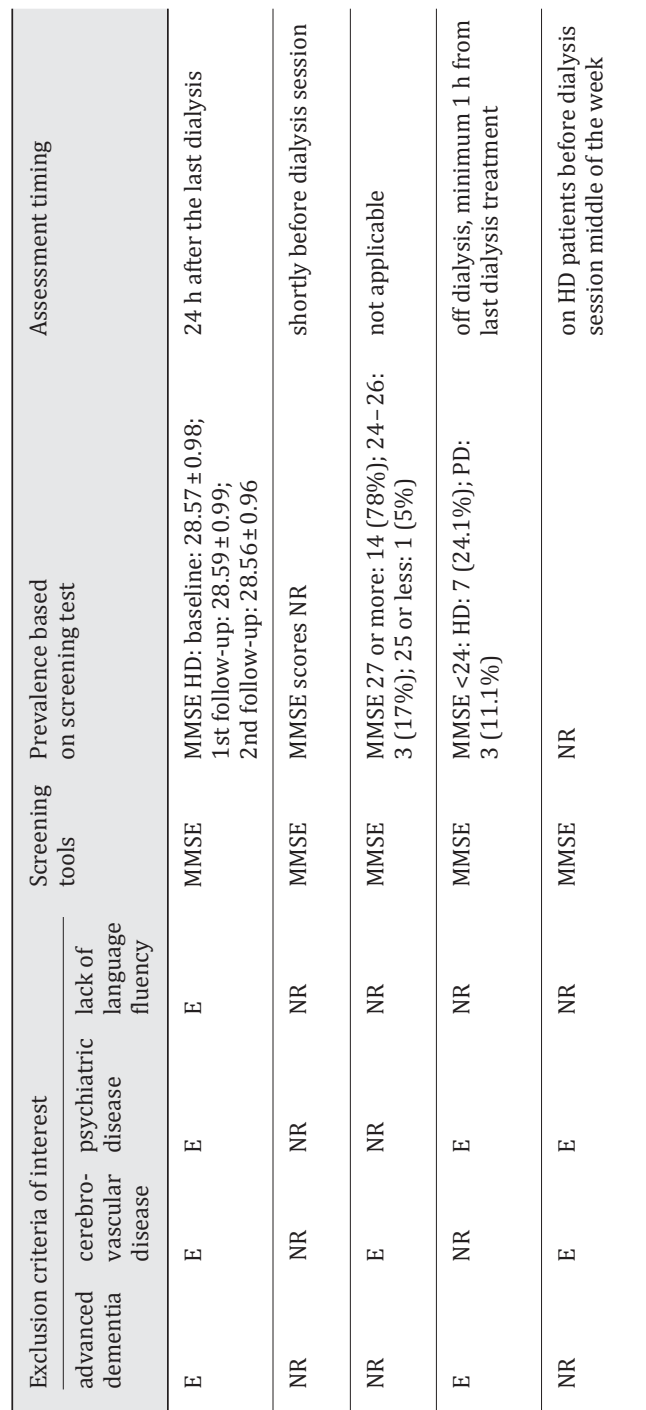

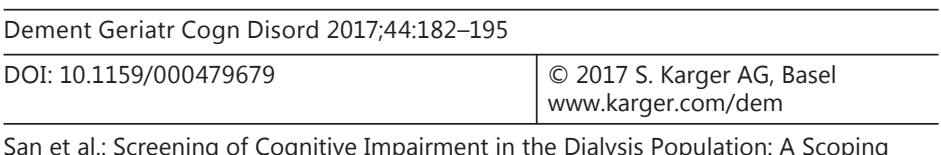


Dementia

and Geriatric
Dement Geriatr Cogn Disord 2017;44:182-195

DOI: 10.1159/000479679

www.karger.com/dem

San et al.: Screening of Cognitive Impairment in the Dialysis Population: A Scoping Review

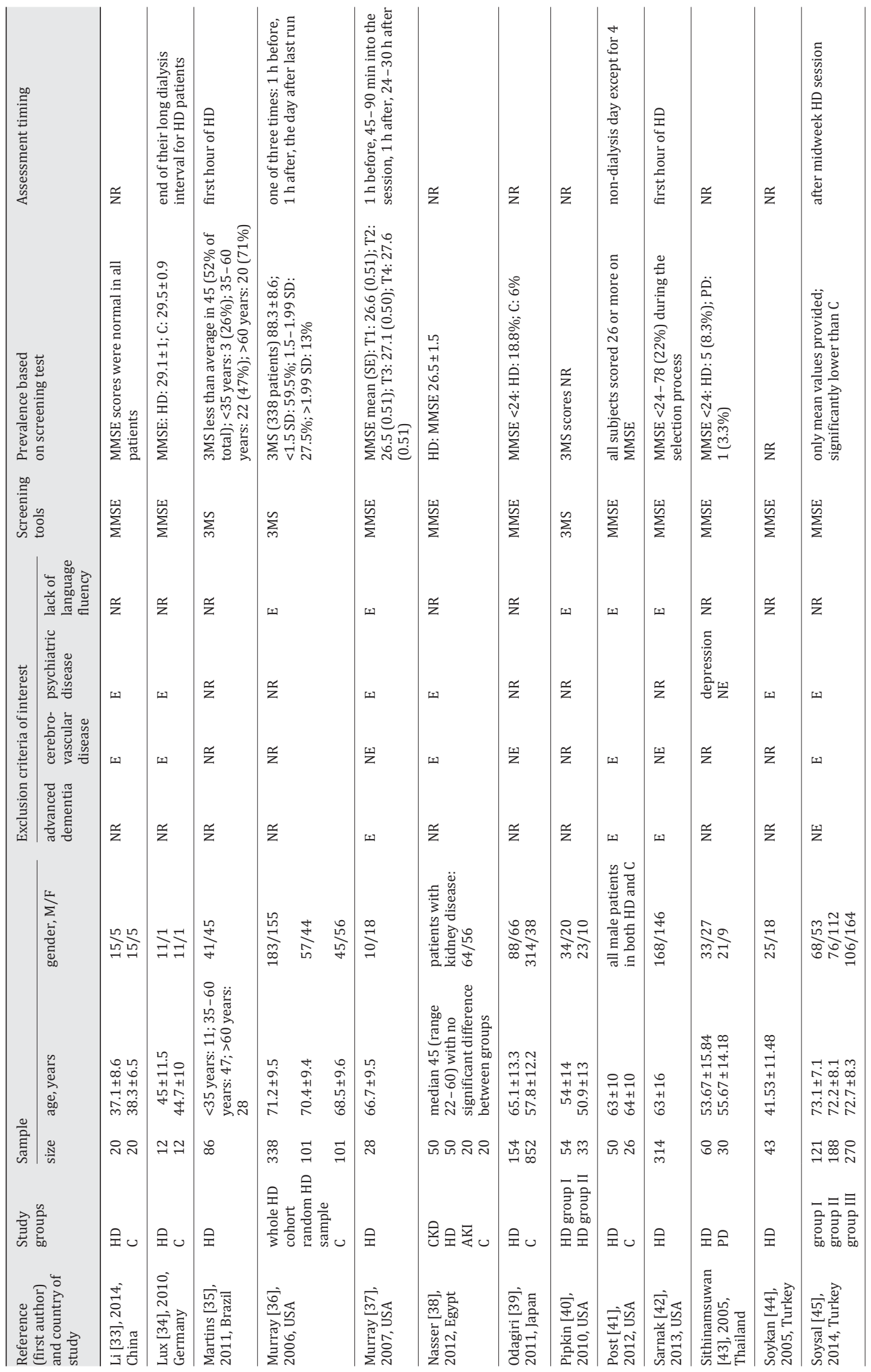


San et al:: Screening of Cognitive Impairment in the Dialysis Population: A Scoping Review

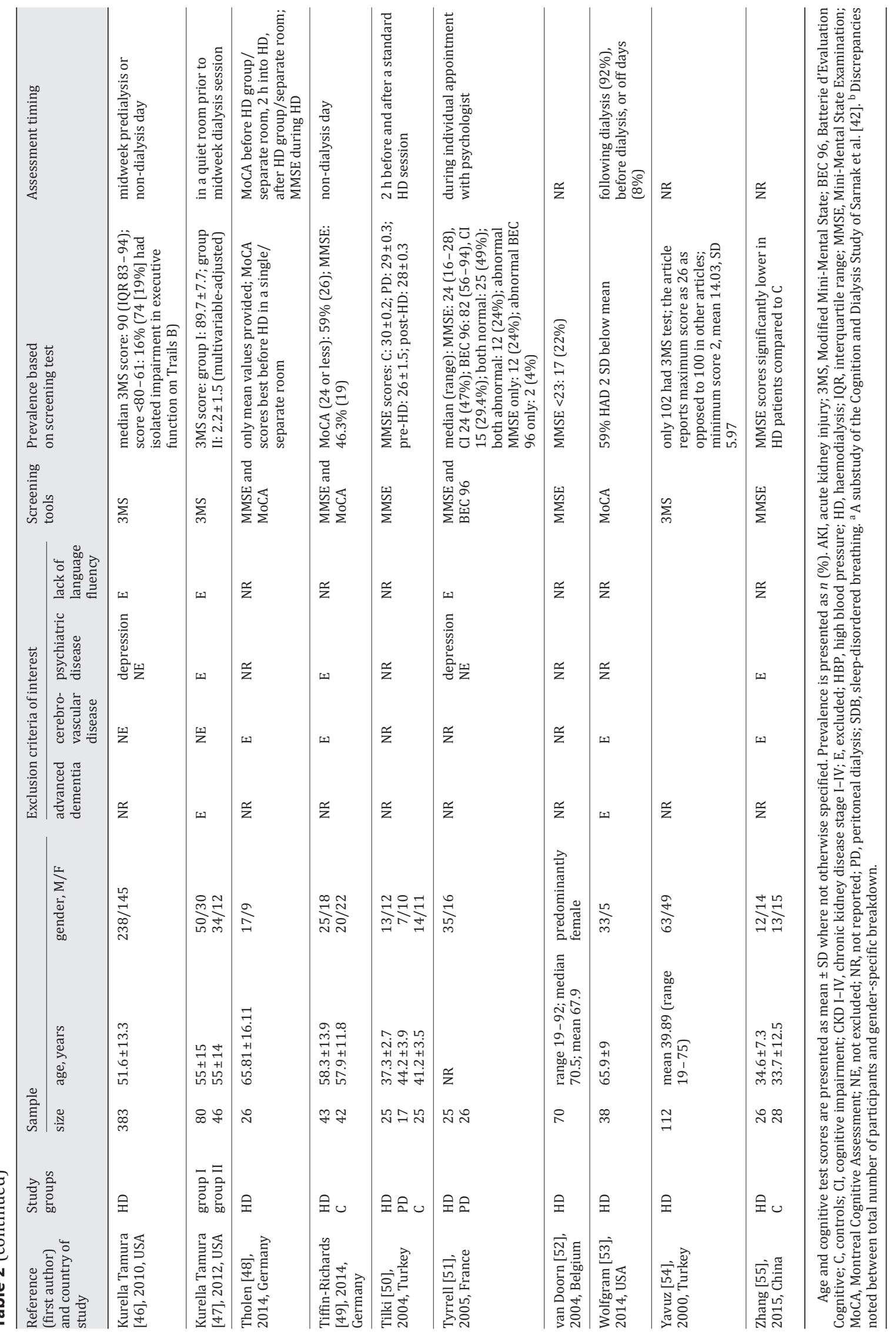


San et al: Screening of Cognitive Impairment in the Dialysis Population: A Scoping Review

The Mini-Mental State Examination (MMSE) [56] as the screening tool, alone or in combination with other tools such as the Montreal Cognitive Assessment (MoCA) [57] or the Batterie d'Evaluation Cognitive (BEC 96) [58], was used in 35 out of the 46 studies. The Modified MiniMental State (3MS) test [59] as the screening tool was used in 9 studies. Only 1 out of 4 studies using the MoCA utilised it as a sole screening tool. Trained researchers or research assistants administered the cognitive screening tools, where reported.

A battery of detailed neuropsychological testing, in addition to the use of a screening tool, was done in 17 out of 46 studies. Only 1 study out of 17 compared the performance of the two screening tools, MMSE and MoCA, with the neuropsychological battery of tests [49]. In this study, the authors reported that there was a greater incidence of detection of cognitive impairment with the neuropsychological test battery (70\%) compared with the MoCA (59\%) and the MMSE (46.3\%). The MoCA for a cut-off value of $\leq 24$ out of 30 was found to be more sensitive and specific in screening for cognitive impairment, with a sensitivity of $76.7 \%$ and a specificity of $78.6 \%$, compared to the MMSE for a cut-off value of $\leq 24$ out of 30 , with a sensitivity of $55.2 \%$ and a specificity of $75.0 \%$. In one study, $66 \%$ of haemodialysis patients had moderate to severe cognitive impairment based on neuropsychological testing, and $59 \%$ of patients scored two standard deviations below the mean on the MoCA [53]. A cross-sectional study of cognitive function in 374 haemodialysis patients aged $\geq 55$ years found a prevalence of cognitive impairment in $87.3 \%$ based on neuropsychological testing and in $40.5 \%$ based on the 3MS [36].

The prevalence of cognitive impairment could not be estimated in 14 out of 28 studies using a screening tool alone to assess global cognitive function. The purpose of these studies was to assess the risk factors for, and correlates of, cognitive impairment and not to estimate its prevalence. The test scores were reported as a continuous variable in their statistical tests. One of the studies, reporting the cognitive scores in the context of detecting early cerebral regional homogeneity changes in neurologically asymptomatic patients, found that none of the 20 patients aged $<50$ years had an abnormal MMSE [33]. In the remaining 13 studies, the prevalence of cognitive impairment varied from 6.6\% [43] to 51\% [11] with MMSE as the screening tool and from $16 \%$ [46] to $39.7 \%$ [20] with 3MS as the screening tool. In two of the studies that compared the prevalence of cognitive impairment in haemodialysis and peritoneal dialysis patients, the difference was not statistically significant $[24,43]$.

There was only 1 study assessing the variation in cognitive performance using a screening tool alone. The study administered MoCA before and after the dialysis session in two different settings, in a group room and in a separate room. It was found that the cognitive performance based on MoCA scores were best when assessed before the dialysis session in a separate room [48]. Three studies on samples of $<100$ participants investigated the timing of cognitive assessment using neuropsychological tests rather than simply screening. However, the results were conflicting. Cognition was best immediately before haemodialysis in one [14], immediately after haemodialysis in the second [15], and $24 \mathrm{~h}$ after haemodialysis in the third [37]. One crossover randomised controlled trial of timing for assessment of cognitive performance using MMSE and detailed neuropsychological tests found no difference in scores between the $1 \mathrm{~h}$ before haemodialysis and the first hour, concluding that assessment before dialysis was appropriate [17].

\section{Discussion}

The most common screening tool administered in the reviewed studies was the MMSE followed by the 3MS and the MoCA. The BEC 96 was only used in 1 study. Since the BEC 96 is hardly known outside the French scientific community, its usefulness as a screening 
instrument was difficult to assess when only English-language articles were reviewed. The MoCA and the MMSE are brief tests, taking $<10$ min to administer, whereas the $3 \mathrm{MS}$ is a more detailed test [60].

The MoCA was specifically designed to detect mild cognitive impairment [57]. It is more sensitive to detecting visuospatial and executive functional deficits than the MMSE and is a better screening test for patients with subcortical vascular cognitive impairment [61]. While Alzheimer disease accounts for up to $80 \%$ of cases of dementia in the general population [62], the high burden of cardiovascular disease in dialysis patients means that the pattern of cognitive impairment is subcortical in nature [63]. In the study by Tiffin-Richards et al. [49], the MoCA with a cut-off value of $\leq 24$ was more sensitive and specific in screening for cognitive impairment in dialysis patients than the MMSE with a cut-off value of $\leq 24$. There were 16 more studies that administered a screening tool as part of a battery of neuropsychological tests for assessment of cognitive dysfunction in dialysis patients. None of these 16 studies assessed the performance of the screening tool used against the battery of neuropsychological tests, which was a lost opportunity. Based on the single study by Tiffin-Richards et al. [49], the MoCA appears to be a preferred screening tool for cognitive impairment in the dialysis population.

The prevalence of cognitive impairment varied widely in the reviewed studies. The variation may be attributed to differing sensitivities of the screening tools, use of different cut-off scores to define cognitive impairment, variable sample size, age, gender, and education level, as well as cultural differences depending on where the study was conducted. The differences in inclusion and exclusion criteria, depending on the purpose of the study, may also explain the variable prevalence. While the prevalence of cognitive impairment in people on dialysis is not clear, 2 systematic reviews found that people with ESKD with or without dialysis consistently had lower scores, indicating a high likelihood of cognitive impairment [5, 64].

In the recently published Choice of Renal Replacement Therapy (CORETH) project, almost half of the 767 eligible dialysis patients had missing cognitive testing data [65]. The patients with missing data were those with disease-related limitations for cognitive testing such as visual, motivational, or motor difficulties. The authors of this study conclude that the estimates of cognitive impairment in the dialysis population may be biased and that the cognitive testing resources that overcome the above limitations may be useful in the future. Excluding patients with previous stroke and patients with dementia also leads to significant underestimation of the prevalence of cognitive impairment in the population studied [66]. Inability to speak a language, for example inability to speak English in studies from the USA $[20,32]$ or French in studies from France [51], was one of the exclusion criteria in many studies. This exclusion may have biased the reported prevalence of cognitive impairment in those studies. Rather than excluding such patients, future studies should consider using validated translations of the selected cognitive screening tool in these patients.

There has been limited investigation into the timing of screening for cognition. Based on one study with a small sample $(n=26)$, the best time and place to communicate information to patients on haemodialysis appears to be before dialysis $[17,48]$ and in a separate room [48]. In practice, the timing of neuropsychological assessment is more likely to be determined by logistics, such as willingness and ability of the patient to participate in a detailed neuropsychological assessment after a haemodialysis session, willingness of patient to come in early for an assessment before haemodialysis session or to visit the hospital or clinic on a non-haemodialysis day, and resources available for a home assessment on a non-haemodialysis day. The timing of cognitive screening in people on dialysis is an area for further investigation.

There is an opposition to screening for cognitive impairment in the general elderly population [67], and routine screening of at-risk populations is not recommended in national 
guidelines [6-8]. One of the reasons for the recommendation against routine screening is that the majority of older people with mild cognitive impairment do not progress to dementia or that their cognitive function may even improve. However, there is compelling evidence that cognitive impairment occurs early in ESKD [64] and that people on dialysis have worse cognition than the general population $[5,64]$. Further, in a recent study of dialysis patients with cognitive impairment, there is evidence that cognition declines faster, with effects on the decision-making capacity [68].

One of the benefits of early diagnosis of cognitive impairment in the dialysis population is identifying substitute decision-makers and facilitating advance care planning. The main advantage of completing an advance care plan under these circumstances is to clearly document a person's wishes with respect to the timing of treatment withdrawal before the person loses decisional capacity and the ability to give informed consent. In the ANZDATA, in 2014 , the cause of death for 1 in 3 dialysis patients was recorded as withdrawal from dialysis [2]. The advance care planning process requires a shared process of decision-making between the patient, the patient's family, and clinicians. When this process begins early, there are opportunities for the patient, family, and clinicians to share their perspectives and negotiate goals of care over several conversations [69]. An early discussion about if and when to withdraw from dialysis therapy can relieve family carers of the burden of responsibility for making the decision on behalf of the person who is cognitively impaired. Currently, the important process of advance care planning remains suboptimal in this population [70].

The Australian Commission on Safety and Quality in Health Care (ACSQHC) "Delirium Clinical Care Standard" recommends cognitive screening at presentation to hospital in patients with key risk factors for delirium such as age $\geq 65$ years, known cognitive impairment/ dementia, severe medical illness, and current hip fracture [71]. Dialysis patients are older, have a large burden of disease, and have a high rate of hospitalisation compared to the general population [72]. The prevalence of cognitive impairment is higher in the dialysis population in the reviewed studies that recruited a control population for cognitive screening. This underscores the need for cognitive screening in the dialysis population to identify patients with delirium and at risk of delirium early in order to institute appropriate management and preventative measures.

Navigating health services places significant cognitive demand on dialysis patients. At every stage of their healthcare journey they need to process, understand, assimilate, and recall information and to be involved in shared decisions about their care. Cognitive impairment is strongly correlated with poor health literacy leading to reduced capacity to engage in self-care and achieve desirable health outcomes [73]. Adherence with complex medication regimens, treatment regimens, dietary restrictions, and fluid restrictions is a major challenge for dialysis patients [74]. Cognitive impairment is linked to decreased adherence to the complex treatment regimen [75]. Early detection of cognitive impairment in the dialysis population will help with successful interventions to overcome the practical barriers faced by these vulnerable patients and improve adherence.

This scoping review was restricted to studies published in English, potentially leading to underrepresentation of the non-English-speaking population and the usefulness of nonEnglish instruments, such as the BEC 96. Through the exclusion of conference abstracts, we may have missed contemporary research on the prevalence or timing. This may limit the applicability of our conclusions. The study did not address the quality of evidence by design and consequently provides a descriptive summary of available research.

The most common screening tool used in the reviewed studies was the MMSE. Based on a single study, the MoCA is more sensitive and specific compared to the MMSE, and the best time to administer the MoCA appears to be before dialysis in a separate room. The reported prevalence of cognitive impairment in dialysis patients is highly variable and is likely to be 
San et al.: Screening of Cognitive Impairment in the Dialysis Population: A Scoping Review

biased due to studies excluding patients with stroke, dementia, and others who could not consent or complete the assessments. There is a need for studies in the dialysis population comparing and validating commonly available cognitive screening tools, including those that are used in culturally and linguistically diverse population.

\section{Disclosure Statement}

The authors have no financial or non-financial affiliations with any organisations in the subject matter or material discussed in this paper.

\section{References}

1 Salomon JA, Wang H, Freeman MK, Vos T, Flaxman AD, Lopez AD, Murray CJ: Healthy life expectancy for 187 countries, 1990-2010: a systematic analysis for the Global Burden Disease Study 2010. Lancet 2013;380: 2144-2162.

2 Australia and New Zealand Dialysis and Transplant Registry: The 39th Annual ANZDATA report, 2016. http:// www.anzdata.org.au/v1/report_2016.html (accessed March 17, 2017).

3 Prince M, Wimo A, Guerchet M, Ali GC, Wu YT, Prina M: World Alzheimer Report 2015. The Global Impact of Dementia: An Analysis of Prevalence, Incidence, Cost and Trends. London, Alzheimer's Disease International, 2015.

4 Kurella Tamura M, Yaffe K: Dementia and cognitive impairment in ESRD: diagnostic and therapeutic strategies. Kidney Int 2011;79:14-22.

5 O'Lone E, Connors M, Masson P, Wu S, Kelly PJ, Gillespie D, et al: Cognition in people with end-stage kidney disease treated with hemodialysis: a systematic review and meta-analysis. Am J Kidney Dis 2016;67:925-935.

6 Guideline Adaptation Committee: Clinical Practice Guidelines and Principles of Care for Dementia. Sydney, NHMRC Partnership Centre for Dealing with Cognitive and Related Functional Decline in Older People, 2016.

7 Canadian Task Force on Preventive Health Care, Pottie K, Rahal R, Jaramillo A, Birtwhistle R, Thombs BD, Singh H, Connor Gorber S, Dunfield L, Shane A, Bacchus M, Bell N, Tonelli M: Recommendations on screening for cognitive impairment in older adults. CMAJ 2016;188:37-46.

8 Moyer VA; U.S. Preventive Services Task Force: Screening for cognitive impairment in older adults: U.S. Preventive Services Task Force recommendation statement. Ann Intern Med 2014;160:791-797.

9 Arksey H, O'Malley L: Scoping studies: towards a methodological framework. Int J Soc Res Meth 2005; 8:19-32.

10 Abdelrahman HM, Elawam AE, Alghitany AN: Cognitive impairment among Egyptian older adults on hemodialysis. Middle East J Age Ageing 2014;11:e24.

11 Bossola M, Ciciarelli C, Di Stasio E, Panocchia N, Conte GL, Rosa F, et al: Relationship between appetite and symptoms of depression and anxiety in patients on chronic hemodialysis. J Ren Nutr 2012;22:27-33.

12 Bossola M, Laudisio A, Antocicco M, Tazza L, Colloca G, Tosato M, Zuccala G: Cognitive performance is associated with left ventricular function in older chronic hemodialysis patients: result of a pilot study. Aging Clin Exp Res 2014;26:445-451.

13 Condé SA, Fernandes N, Santos FR, Chouab A, Mota MM, Bastos MG: Cognitive decline, depression and quality of life in patients at different stages of chronic kidney disease. J Bras Nefrol 2010;32:242-248.

14 Costa AS, Tiffin-Richards FE, Holschbach B, Frank RD, Vassiladou A, Kruger T, et al: Clinical predictors of individual cognitive fluctuations in patients undergoing hemodialysis. Am J Kidney Dis 2014;64:434-442.

15 Cukor D, Ver Halen N, Rosenthal Asher D, Goldberg MA, Slyker J, Kimmel PL: A pilot investigation of cognitive improvement across a single hemodialysis treatment. J Nephrol 2013;26:323-330.

16 Dahbour SS, Wahbeh AM, Hamdan MZ: Mini mental status examination (MMSE) in stable chronic renal failure patients on hemodialysis: the effects of hemodialysis on the MMSE score. A prospective study. Hemodial Int 2009;13:80-85.

17 Drew DA, Tighiouart H, Scott TM, Lou KV, Shaffi K, Weiner DE, Sarnak MJ: Cognitive performance before and during hemodialysis: a randomized cross-over trial. Nephron Clin Pract 2013;124:151-158.

18 Fadili W, Al Adlouni A, Louhab N, Habib Allah M, Kissani N, Laouad I: Prevalence and risk factors of cognitive dysfunction in chronic hemodialysis patients. Aging Ment Health 2014;18:207-211.

19 Gad AH, Ramzy GM, Abdelhamid YM, El Massry HA, Masoud MM: Cognitive impairment in hemodialysis patients. Egypt J Neurol Psychiat Neurosurg 2012;49:245-249.

20 Hain DJ: Cognitive function and adherence of older adults undergoing hemodialysis. Nephrol Nurs J 2008;35: 23-29.

21 Harciarek M, Williamson JB, Biedunkiewicz B, Lichodziejewska-Niemierko M, Debska-Slizien A, Rutkowski B: Risk factors for selective cognitive decline in dialyzed patients with end-stage renal disease: evidence from verbal fluency analysis. J Int Neuropsychol Soc 2012;18:162-167. 
San et al.: Screening of Cognitive Impairment in the Dialysis Population: A Scoping Review

22 Huang YC, Kuo YW, Lee TH, Lee M, Hsiao MC, Wang CL, Lee JD: Hypoalbuminemia and not hyperhomocysteinemia as a risk factor for dementia in hemodialysis patients. J Ren Nutr 2008;18:347-354.

23 Isshiki R, Kobayashi S, Iwagami M, Tsutumi D, Mochida Y, Isioka K, et al: Cerebral blood flow in patients with peritoneal dialysis by an easy Z-score imaging system for brain perfusion single-photon emission tomography. Ther Apher Dial 2014;18:291-296.

24 Jung S, Lee YK, Choi SR, Hwang SH, Noh JW: Relationship between cognitive impairment and depression in dialysis patients. Yonsei Med J 2013;54:1447-1453.

25 Kalaitzidis RG, Karasavvidou D, Tatsioni A, Balafa O, Pappas K, Spanos G, et al: Risk factors for cognitive dysfunction in CKD and hypertensive subjects. Int Urol Nephrol 2013;45:1637-1646.

26 Kalirao P, Pederson S, Foley RN, Kolste A, Tupper D, Zaun D, et al: Cognitive impairment in peritoneal dialysis patients. Am J Kidney Dis 2011;57:612-620.

27 Kang EW, Abdel-Kader K, Yabes J, Glover K, Unruh M: Association of sleep-disordered breathing with cognitive dysfunction in CKD stages 4-5. Am J Kidney Dis 2012;60:949-958.

28 Kato M, Kawaguchi K, Nakai S, Murakami K, Hori H, Ohashi A, et al: Potential therapeutic system for Alzheimer's disease: removal of blood $A \beta s$ by hemodialyzers and its effect on the cognitive functions of renal-failure patients. J Neural Transm (Vienna) 2012;119:1533-1544.

29 Kitaguchi N, Kawaguchi K, Nakai S, Murakami K, Ito S, Hoshino H, et al: Reduction of Alzheimer's disease amyloid-beta in plasma by hemodialysis and its relation to cognitive functions. Blood Purif 2011;32:57-62.

30 Kobayashi S, Mochida Y, Ishioka K, Oka M, Maesato K, Moriya H, et al: The effects of blood pressure and the renin-angiotensin-aldosterone system on regional cerebral blood flow and cognitive impairment in dialysis patients. Hypertens Res 2014;37:636-641.

31 Kutlay S, Nergizoglu G, Duman N, Atli T, Keven K, Ertürk S, et al: Recognition of neurocognitive dysfunction in chronic hemodialysis patients. Ren Fail 2001;23:781-787.

32 Leinau L, Murphy TE, Bradley E, Fried T: Relationship between conditions addressed by hemodialysis guidelines and non-ESRD-specific conditions affecting quality of life. Clin J Am Soc Nephrol 2009;4:572-578.

33 Li C, Su H, Qiu Y, Lu XF, Shen S, Zhan WF, et al: Regional homogeneity changes in hemodialysis patients with end stage renal disease: in vivo resting-state functional MRI study. PLoS One 2014; 9:e87114.

34 Lux S, Mirzazade S, Kuzmanovic B, Plewan T, Eickhoff SB, Shah NJ, et al: Differential activation of memoryrelevant brain regions during a dialysis cycle. Kidney Int 2010;78:794-802.

35 Martins CT, Ramos GS, Guaraldo SA, Uezima CB, Martins JP, Ribeiro Junior E: Comparison of cognitive function between patients on chronic hemodialysis who carry out assisted physical activity and inactive ones. J Bras Nefrol 2011;33:27-30.

36 Murray AM, Tupper DE, Knopman DS, Gilbertson DT, Pederson SL, Li S, et al: Cognitive impairment in hemodialysis patients is common. Neurology 2006;67:216-223.

37 Murray AM, Pederson SL, Tupper DE, Hochhalter AK, Miller WA, Li Q, et al: Acute variation in cognitive function in hemodialysis patients: a cohort study with repeated measures. Am J Kidney Dis 2007;50:270-278.

38 Nasser ME, Shawki S, El Shahawy Y, Sany D: Assessment of cognitive dysfunction in kidney disease. Saudi J Kidney Dis Transpl 2012;23:1208-1214.

39 Odagiri G, Sugawara N, Kikuchi A, Takahashi I, Umeda T, Saitoh H, et al: Cognitive function among hemodialysis patients in Japan. Ann Gen Psychiatry 2011;10:20.

40 Pipkin M, Eggers PW, Larive B, Rocco V, Stokes JB, Suri RS, et al: Recruitment and training for home hemodialysis: experience and lessons from the Nocturnal Dialysis Trial. Clin J Am Soc Nephrol 2010;5:1614-1620.

41 Post JB, Morin KG, Sano M, Jegede AB, Langhoff E, Spungen AM: Increased presence of cognitive impairment in hemodialysis patients in the absence of neurological events. Am J Nephrol 2012;35:120-126.

42 Sarnak MJ, Tighiouart H, Scott TM, Lou KV, Sorensen EP, Giang LM, et al: Frequency of and risk factors for poor cognitive performance in hemodialysis patients. Neurology 2013;80:471-480.

43 Sithinamsuwan P, Niyasom S, Nidhinandana S, Supasyndh O: Dementia and depression in end stage renal disease: comparison between hemodialysis and continuous ambulatory peritoneal dialysis. J Med Assoc Thai 2005;88(suppl 3):S141-S147.

44 Soykan A, Boztas H, Kutlay S, Ince E, Nergizoglu G, Dilekoz AY, Berksun O: Do sexual dysfunctions get better during dialysis? Results of a six-month prospective follow-up study from Turkey. Int J Impot Res 2005;17: 359-363.

45 Soysal P, Isik AT, Buyukaydin B, Kazancioglu R: A comparison of end-stage renal disease and Alzheimer's disease in the elderly through a comprehensive geriatric assessment. Int Urol Nephrol 2014;46:1627-1632.

46 Kurella Tamura M, Larive B, Unruh ML, Stokes JB, Nissenson A, Mehta RL, et al: Prevalence and correlates of cognitive impairment in hemodialysis patients: the Frequent Hemodialysis Network trials. Clin J Am Soc Nephrol 2010;5:1429-1438.

47 Kurella Tamura M, Meyer JB, Saxena AB, Huh JW, Wadley VG, Schiller B: Prevalence and significance of stroke symptoms among patients receiving maintenance dialysis. Neurology 2012;79:981-987.

48 Tholen S, Schmaderer C, Kusmenkov E, Chmielewski S, Forsti H, Kehl V, et al: Variability of cognitive performance during hemodialysis: standardization of cognitive assessment. Dement Geriatr Cogn Disord 2014;38: 31-38.

49 Tiffin-Richards FE, Costa AS, Holschbach B, Frank RD, Vassiliadou A, Kruger T, et al: The Montreal Cognitive Assessment (MoCA) - a sensitive screening instrument for detecting cognitive impairment in chronic hemodialysis patients. PLoS One 2014;9:e106700. 
San et al.: Screening of Cognitive Impairment in the Dialysis Population: A Scoping Review

50 Tilki HE, Akpolat T, Tunalı G, Kara A, Onar MK: Effects of haemodialysis and continuous ambulatory peritoneal dialysis on P300 cognitive potentials in uraemic patients. Ups J Med Sci 2004;109:43-48.

51 Tyrrell J, Paturel L, Cadec B, Capezzali E, Poussin G: Older patients undergoing dialysis treatment: cognitive functioning, depressive mood and health-related quality of life. Aging Ment Health 2005;9:374-379.

52 van Doorn KJ, Heylen M, Mets T, Verbeelen D: Evaluation of functional and mental state and quality of life in chronic haemodialysis patients. Int Urol Nephrol 2004;36:263-267.

53 Wolfgram DF, Sunio L, Vogt E, Smith HM, Visotcky A, Laud P, Whittle J: Haemodynamics during dialysis and cognitive performance. Nephrology (Carlton) 2014;19:771-776.

54 Yavuz N, Karataş M, Kilinç S: Correlates for end-stage renal disease patients. Scand J Caring Sci 2000;14:179183.

55 Zhang R, Liu K, Yang L, Zhou T, Qian S, Li B, et al: Reduced white matter integrity and cognitive deficits in maintenance hemodialysis ESRD patients: a diffusion-tensor study. Eur Radiol 2015;25:661-668.

56 Molloy D, Standish TI: A guide to the standardized Mini-Mental State Examination. Int Psychogeriatr 1997; 9(suppl 1):87-94.

57 Nasreddine ZS, Phillips NA, Bedirian V, Charbonneau S, Whitehead V, Collin I, et al: The Montreal Cognitive Assessment, MoCA: a brief screening tool for mild cognitive impairment. J Am Geriatr Soc 2005;53:695-699.

58 Signoret JL: Evaluation des troubles de la mémoire et des désordres cognitifs associés: BEC 96. Paris, Editions IPSEN, 1989.

59 Teng EL, Chui HC: The Modified Mini-Mental State (3MS) examination. J Clin Psychiatry 1987;48:314-318.

60 Tsoi KK, Chan JY, Hirai HW, Wong SY, Kwok TC: Cognitive tests to detect dementia: a systematic review and meta-analysis. JAMA Intern Med 2015;175:1450-1458.

61 Ihara M, Okamoto Y, Takahashi R: Suitability of the Montreal Cognitive Assessment versus the Mini-Mental State Examination in detecting vascular cognitive impairment. J Stroke Cerebrovasc Dis 2013;22:737-741.

62 Australian Institute of Health and Welfare: Australia's Health 2016. Australia's Health Series No. 15. Cat. No. AUS199. Canberra, AIHW, 2016.

63 Pereira AA, Weiner DE, Scott T, Chandra P, Bluestein R, Griffith J, Sarnak MJ: Subcortical cognitive impairment in dialysis patients. Hemodial Int 2007;11:309-314.

64 Berger I, Wu S, Masson P, Kelly PJ, Duthie FA, Whiteley W, et al: Cognition in chronic kidney disease: a systematic review and meta-analysis. BMC Med 2016;14:206.

65 Neumann D, Robinski M, Mau W, Girndt M: Cognitive testing in patients with CKD: the problem of missing cases. Clin J Am Soc Nephrol 2017;12:391-398.

66 Corraini P, Henderson VW, Ording AG, Pedersen L, Horváth-Puhó E, Sørensen HT: Long-term risk of dementia among survivors of ischemic or hemorrhagic stroke. Stroke 2017;48:180-186.

67 Le Couteur D, Doust JA, Creasey H, Brayne C: Political drive to screen for pre-dementia: not evidence based and ignores the harms of diagnosis. BMJ 2013;347:f5125.

68 Iyasere 0, Okai D, Brown E: Cognitive function and advanced kidney disease: longitudinal trends and impact on decision-making. Clin Kidney J 2017;10:89-94.

69 Manalo MFC: End-of-life decisions about withholding or withdrawing therapy: medical, ethical, and religiocultural considerations. Palliat Care 2013;7:1-5.

70 Goff SL, Eneanya ND, Feinberg R, Germain MJ, Marr L, Berzoff J, et al: Advance care planning: a qualitative study of dialysis patients and families. Clin J Am Soc Nephrol 2015;10:390-400.

71 Australian Commission on Safety and Quality in Health Care: Delirium Clinical Care Standard. Sydney, ACSQHC, 2016.

72 Mathew AT, Strippoli GF, Ruospo M, Fishbane S: Reducing hospital readmissions in patients with end-stage kidney disease. Kidney Int 2015;88:1250-1260.

73 Wolf MS, Curtis LM, Wilson EAH, Revelle W, Waite KR, Smith SG, et al: Literacy, cognitive function, and health: results of the LitCog study. J Gen Intern Med 2012;27:1300-1307.

74 Kammerer K, Garry G, Hartigan M, Carter B, Erlich L: Adherence in patients on dialysis: strategies for success. Nephrol Nurs J 2007;34:479-486.

75 Campbell N, Boustani MA, Skopelja EN, Gao S, Unverzagt FW, Murray MD: Medication adherence in older adults with cognitive impairment: a systematic evidence-based review. Am J Geriatr Pharmacother 2012;10: 165-177. 